\title{
A INTERNACIONALIZAÇÃO DOS DIREITOS HUMANOS E A RETOMADA DAS PRÁTICAS RESTAURATIVAS NO PROCESSO PENAL
}

\author{
Álisson Thiago de Assis Campos* \\ Deilton Ribeiro Brasil ${ }^{* *}$
}

Resumo: A Justiça Restaurativa refere-se à implementação de sistemas que permitem a participação do ofendido e ofensor na construção de soluções para conflitos oriundos do crime. Se antigamente tais conflitos eram resolvidos pessoalmente pelas partes envolvidas, verificouse que ao longo dos anos houve certo alijamento da vítima do referido processo. Após a $2^{\mathrm{a}}$ Guerra Mundial iniciou-se um processo de internacionalização dos Direitos Humanos que influenciado pelos movimentos vitimológicos, preocupou-se com proteção da vítima. A metodologia deste trabalho é baseada na revisão de literatura e busca demonstrar a relação entre as práticas restaurativas e o processo de internacionalização dos Direitos.

Palavras-Chave: Justiça Restaurativa; Direitos Humanos; Vítima; Internacionalização; ONU.

\section{THE INTERNATIONALIZATION OF HUMAN RIGHTS AND THE USE OF RESTORATIVE PRACTICES IN THE CRIMINAL PROCEDURE}

\begin{abstract}
Restorative Justice refers to the implementation of systems that allows the offended and offender to participate in the construction of solutions to criminal conflicts. In the past such conflicts were resolved personally by the parties involved, but over the years there has been the exclusion of the victim. After the Second World War, a process of internationalization of Human Rights began, influenced by the victim's movements and concerned with the protection of the victim. The survey methodology of this paper is based on literature review and aims to demonstrate the relationship between restorative practices and the process of internationalization of Human Rights.
\end{abstract}

Keywords: Restorative Justice; Human Rights; Victim; Internationalization; UN.

\section{INTRODUÇÃO}

O presente artigo tem como propósito contribuir para o estudo da temática envolvendo a participação da vítima na resolução de conflitos, analisando a importância das práticas

\footnotetext{
* Mestrando do PPGD-Mestrado em Proteção dos Direitos Fundamentais da Universidade de Itaúna-UIT. Especialista em Ciências Penais pela Universidade Anhanguera-UNIDERP. E-mail: alissonateticano@ gmail.com. CV: http://lattes.cnpq.br/7493698275051596

** Pós-Doutor em Direito pela Università degli Studi di Messina, Itália. Doutor em Direito pela UGF/RJ. Professor da Graduação e do PPGD- Mestrado em Proteção dos Direitos Fundamentais da Universidade de Itaúna-MG. Email: deilton.ribeiro@terra.com.br. CV: http://lattes.cnpq.br/1342540205762285
} 
restaurativas e identificando suas relações com o movimento de expansão de Direitos Humanos ocorrido, sobretudo, na segunda metade do século XX, após o término da $2^{\text {a }}$ Guerra Mundial.

Desde a nova concepção sobre o estudo da vítima desenvolvida por Benjamim Mendelsohn ${ }^{1}$, a quem se atribuiu a conceituação da Vitimologia, a relação vítima/delinquente deixou de ser polarizada e antagônica para se tornar mais complexa, abrangente e interdisciplinar, envolvendo não só aspectos jurídicos mas também sociais e psicológicos.

Para alcançar os objetivos acima estipulados, será realizada uma revisão de literatura com a releitura de doutrinas que se dedicam a conceituar a Justiça Restaurativa e a vitimologia, como as obras de autores como Howard Zehr e Neemias Moretti Prudente que já investigaram em diversas obras sobre o tema da implementação de práticas restaurativas no âmbito jurídico.

A fim de possibilitar uma maior compreensão sobre a importância da participação da vítima dentro do processo penal, serão utilizadas as obras de Edgar Hrycylo Bianchini e Vanessa de Biassio Mazzutti buscando, ainda, verificar se existem pontos de conexão entre o incentivo à implementação de práticas restaurativas no processo penal e os movimentos expansionistas dos Direitos Humanos ocorridos após o término da $2^{\mathrm{a}}$ Guerra Mundial e a criação das Nações Unidas. Completar-se-á a pavimentação teórica com uma leitura em Valério Mazzuoli e Flávia Piovesan onde se procura discutir acerca do movimento de internacionalização dos Direitos Humanos e sua influência no incentivo à efetivação de práticas restaurativas.

Fundamental ainda destacar a realização de uma abordagem acerca do conceito e da evolução histórica da Justiça Restaurativa, identificando a necessidade de proteção da vítima através de mecanismos eficazes e que atendam aos interesses e expectativas do ofendido.

Também será analisado como se dá o incentivo à participação das vítimas na resolução dos conflitos penais, sobretudo no âmbito das organizações internacionais. Nesse contexto, avaliar-se-á se a retomada do protagonismo do ofendido na resolução de conflitos apresenta-se como consequência do processo de internacionalização dos Direitos Humanos que incentivou a criação de mecanismos de proteção aos direitos dos ofendidos ao redor do planeta.

\section{DA METODOLOGIA UTILIZADA}

\footnotetext{
${ }^{1}$ A vitimologia ganhou força após a $2^{\text {a }}$ Guerra Mundial e o martírio sofrido por judeus nos campos de concentração. $\mathrm{O}$ advogado israelita, Benjamin Mendelsohn foi um dos principais incentivadores das ideias.
} 
A metodologia empregada para o desenvolvimento da pesquisa baseou-se no método descritivo e analítico que permitiu a abordagem, análise e conceituação das categorias consideradas fundamentais para o desenvolvimento dos temas relativos ao processo de internacionalização dos Direitos Humanos e a forma como este incentivou a implementação da Justiça Restaurativa.

Partindo de uma revisão de literatura baseada na releitura dos principais doutrinadores que versam sobre a temática proposta e, ainda, mediante uma análise aprofundada do arcabouço jurídico que incentiva a efetivação da Justiça Restaurativa e a proteção/participação da vítima na resolução dos conflitos no âmbito internacional, onde se realizou um exame conceitual dos aspectos relacionados à temática. O levantamento bibliográfico forneceu as bases teóricas necessárias para a elaboração adequada do trabalho, além dos conceitos de ordem dogmática que foram utilizados.

\section{JUSTIÇA RESTAURATIVA: CONCEITO E EVOLUÇÃO HISTÓRICA}

Embora ainda seja um paradigma em construção, a Justiça Restaurativa é conceituada por Prudente (2011, p. 42) como sendo "uma nova forma de resolução de conflito em que as próprias partes envolvidas num conflito específico (vítima, infrator e comunidade - primária e/ou secundária) se encontram e buscam, por meio do diálogo/consenso, e com a ajuda de um facilitador capacitado, a solução da divergência".

Seguindo esta mesma linha de raciocínio, Brasil (2014, p. 157) defende que a Justiça Restaurativa é uma forma de ampliar "o círculo dos interessados no processo (aqueles que foram afetados ou têm uma posição em relação ao evento ou ao caso) para além do Estado e do ofensor, incluindo também as vítimas e os membros da comunidade".

Partindo dos pressupostos acima destacados, o Conselho Econômico e Social da ONU, por meio da Resolução n ${ }^{0}$ 12/2002, incentivou a efetivação da Justiça Restaurativa e definiu o processo restaurativo como sendo aquele "no qual a vítima e o ofensor, e, quando apropriado, quaisquer outros indivíduos ou membros da comunidade afetados por um crime participam ativamente na resolução das questões oriundas do crime, geralmente com a ajuda de um facilitador" (ONU, 2002).

Atuando ativamente na composição de um conflito, as vítimas acabam ampliando a possibilidade de efetivação de suas pretensões dentro de um processo judicial, legitimando a 
atuação do Estado e permitindo a concretude de um enfoque mais humanizado e democrático, voltado à proteção do interesse de todos os indivíduos envolvidos com as questões complexas postas à apreciação do Poder Judiciário.

Historicamente as bases da expressão "Justiça Restaurativa" remontam à década de 1950, quando o psicólogo norte-americano Albert Eglash deu início à implementação de um modelo diferenciado para reabilitação dos criminosos a partir da busca pelo perdão de sua vítima (BIANCHINI, 2012, p. 88). Posteriormente, em 1977, Eglash publicou um ensaio denominado "Beyond Restitution: creative restitution" em que apadrinhou o termo ora analisado e, por essa razão passou a ser considerado como o grande precursor dos ideais restaurativos na forma como hoje é estudada no ambiente acadêmico.

Vale lembrar, entretanto, que muito embora a criação do termo "Justiça Restaurativa seja creditada a Albert Eglash,

\begin{abstract}
a concepção de justiça a que ele se referia não era nova. A justiça restaurativa não é um movimento de "nova onda" à margem da prática jurídica. Suas concepções de justiça têm sido mais ou menos proeminentes durante a maior parte da história. Como diz o criminologista John Braithwaite, "a justiça restaurativa tem sido o modelo dominante da justiça penal em toda a história da humanidade para todos os povos do mundo". As concepções da Justiça Restaurativa reivindicam suas raízes nas tradições ocidentais e não-ocidentais. Assim, um movimento em direção a um modelo restaurador da justiça talvez seja melhor entendido como um retorno às raízes da justiça, e não como uma nova "cura" para um sistema enfermo. (LLEWELLYN; HOWSE, p. 04), (Tradução livre)
\end{abstract}

Conforme se verifica até aqui, a Justiça Restaurativa incentiva a participação da vítima na busca de uma solução consensual para o fenômeno criminal. Suas raízes são antigas e remontam ao próprio surgimento dos meios primitivos de resolução de conflito, onde vítima e ofensor exerciam os papéis principais na solução das contendas.

Ocorre, entretanto, que o desenvolvimento da sociedade culminou no monopólio estatal do ius puniendi, impedindo a realização da vingança privada. Nesse processo, a vítima foi deixada à margem do processo de construção das soluções para os casos envolvendo questões criminais.

No modelo punitivo quem sofre a lesão é deixado de lado, isto é, que não é considerada pessoa lesionada, mas como um sinal da possibilidade de intervenção do poder das agências do sistema penal (que intervém quando ele quer e trabalha sem levar em conta a vontade do lesionado).

$[\ldots]$

O pretexto para limitar a vingança da vítima ou complementar sua fraqueza serve para governar sua personalidade, jogar para baixo a humanidade. A 
Invocação à dor da vítima é apenas uma oportunidade para o exercício de um poder cuja seletividade estrutural the torna arbitrário e caprichoso (ZAFFARONI; ALAGIA; SLOKAR, 2002, p. 230).

Ao que parece, a perspectiva da vítima e seus interesses foram deixados de lado na solução dos conflitos. O Estado, ao tomar para si a exclusividade do poder de punir, acabou sendo responsável pelo apagamento da vítima dentro do processo de persecução penal.

Surge, daí, a necessidade de se verificar como se deu, ao longo dos anos, o início do processo de retomada do protagonismo da vítima dentro do processo penal. Embora o fenômeno ainda seja incipiente, constata-se que ele já se faz notar em nosso meio, inclusive por algumas modificações legislativas e pelo incentivo à efetivação de práticas restaurativas que sugerem a participação do ofendido no processo de construção de soluções para as mais diversas questões penais que possam vir a surgir.

\section{BREVE ESCORÇO SOBRE PARTICIPAÇÃO DA VÍTIMA NA RESOLUÇÃO DE CONFLITOS}

Nas sociedades primitivas a vítima exercia um protagonismo máximo na resolução de conflitos. $\mathrm{O}$ indivíduo, às vezes representado por seu clã ou grupo, tinha o direito de responder pessoalmente a uma conduta que lhe desagradasse, estando limitado unicamente por sua força física e compleição para efetivar a sua vontade e suas pretensões em relação às ofensas contra ele praticadas (FRADE, 2011).

Com o fortalecimento do poder central e sua consequente burocratização, o Estado passou a limitar as possibilidades de vingança privada, tomando para si o ius puniendi. Esse movimento foi responsável pela substituição da vingança privada (aqui compreendida como emprego da força individual em resposta a uma ofensa) por sanções estabelecidas de maneira prévia, abstrata e genérica. Surgiu, então, o "direito penal moderno que efetivamente se torna responsável pelo apagamento da vítima” (FRADE, 2011, p. 09).

No processo de evolução estatal acima descrito, a agressão do ofensor contra a vítima deixou de ser encarada como uma afronta de um indivíduo contra o outro, passando a ser interpretada como um atentado à autoridade e a legitimidade do próprio poder soberano. Tal entendimento garantiria ao Estado uma prerrogativa absoluta de processar, julgar e punir os desviantes da maneira como o seu ordenamento jurídico estipulasse. Nesse contexto, a vítima 
perdeu relevância dentro do processo, sendo que seus interesses e perspectivas acabaram sendo descartados e substituídos pela vontade do Estado.

A vítima passou a ser no campo penal meramente um sujeito passivo, que
quando procura as autoridades para relatar seu infortúnio corre o risco de ser
tratada com frieza profissional. Em determinadas ocasiões pode vir a ser alvo
da desconfiança acerca das informações que presta sobre as circunstâncias em
que foi vitimizada. Em outras ocasiões pode vir a ser objeto do desprezo por
sua demonstrada fraqueza. E no decorrer da persecução penal espera-se dela
um comportamento que não diminua as chances de sucesso da persecução
penal, sem que tenha oportunidade de manifestar sua vontade. [...]
A relação entre Estado e vítima passou a ser pautada pelos seus deveres de
comparecer quando convocada para os atos processuais, colaborar com a
instrução probatória e apoiar a acusação, mesmo que não entenda ser relevante
para seus interesses e ainda quando a tenha o temor de sofrer retaliações
(FRADE, 2011, p. 10).

O paradigma que concedeu ao Estado o poder/dever de punir em desconsideração à vontade da vítima não se estabeleceu sem censuras mesmo porque tal modelo acabou transformando os ofendidos em verdadeiros objetos a serem utilizados de maneira indiscriminada em favor da máquina punitiva estatal, desconsiderando, quase que por completo, os seus interesses e anseios dentro da sistemática de punição elaborada pelos gestores estatais.

Para Mazzutti (2012, p. 67), "diversas críticas ao sistema penal surgiram a partir da constatação de que as necessidades e expectativas da vítima não eram levadas em consideração, fazendo com que o conflito fosse despersonalizado, vez que o sistema penal o subtraía das partes". Conclui-se, pois, que a evolução e modernização do sistema penal fez com que a relação entre o Estado e a vítima fosse reduzida ao simples comparecimento nos atos processuais, à colaboração na produção das provas e ao apoio à acusação (que em muitos casos se desenvolve independentemente de sua vontade).

Em contraposição ao arquétipo acima apresentado, o surgimento do movimento vitimológico representou um inegável avanço na compreensão do fenômeno da criminalidade e no reconhecimento da vítima como parte fundamental da lide penal.

Se a princípio as pretensões das vítimas estavam relegadas a um segundo plano, o estudo da vitimologia foi responsável por trazer os ofendidos novamente para o centro dos debates processuais penais, fazendo com que uma série de medidas fossem adotadas no sentido de se garantir a proteção das vítimas e a efetivação de seus interesses dentro dos procedimentos de construção das decisões, permitindo certo grau de consenso e democraticidade ao palco de solução dos conflitos. 
Conforme Oliveira (1999, p. 115), todas as iniciativas em favor dos direitos das vítimas

\begin{abstract}
surgiram diante de uma nova visão dos direitos das vítimas que, ignoradas pelo sistema penal, durante tanto tempo direcionado unicamente para o criminoso, e desamparadas pelo poder público, reivindicavam uma maior atenção ao reconhecimento de seus direitos, assunto permanente em todos os simpósios internacionais de vitimologia.
\end{abstract}

Com o avanço da vitimologia o ofendido voltou a ser visto como um ser capaz de identificar e garantir seus próprios interesses, o que proporcionou a sua revalorização dentro da sistemática processual de resolução dos conflitos penais.

De acordo com García-Pablos, o movimento vitimológico

persegue uma redefinição global do status da vítima e de suas relações com o delinquente, com o sistema legal, a sociedade, os poderes públicos, a ação política (econômica, social, assistencial, etc.). Identificar, em consequência, as expectativas da vítima, assim como a valiosa contribuição que cabe esperar dos numerosos estudos científicos sobre a mesma, com pretensões monetárias, mercantilistas, representa uma manipulação simplificadora que a realidade empírica desmente. Pois os estudos científicos demonstram abundantemente - se se realizam com uma razoável imediação temporal em relação ao delito - que o que a vítima mais espera e exige é justiça e não uma compensação econômica. (GARCIA-PABLOS apud MAZZUTTI, 2012, p. 68).

Dessa maneira, mais do que um mero estudo teórico da vítima, o movimento vitimológico está voltado à criação e implementação de mecanismos de proteção e efetivação de direitos humanos, centrando-se na busca de medidas para conferir apoio e segurança aos ofendidos. Além do mais, o referido movimento busca garantir à vítima a possibilidade de intervir e participar ativamente na construção e elaboração das decisões judiciais, o que torna o processo mais democrático e causa uma sensação de satisfação muito maior, sobretudo porque atende aos interesses de todas as partes envolvidas direta e indiretamente no caso concreto.

Algumas das principais contribuições que a vitimologia ofereceu ao Direito foi a ideia de que a vítima, na condição de principal afetada pela ofensa ocasionada por alguém, deve ser atendida em suas expectativas. Surge, daí, a necessidade de fazer com que qualquer decisão judicial seja construída a partir da inclusão dos interesses e perspectivas vitimológica, levandose em conta não só a vontade do Estado, mas também as preocupações do ofendido que, na verdade, é quem vê sua vida diretamente afetada pela ilicitude que dá ensejo a um processo criminal. 
No contexto acima apresentado, a vítima deve ser encarada como sujeito detentor de direitos dentro da instrução do processo, razão pela qual surge a necessidade de se garantir meios de participação mais efetiva dentro da arquitetura normativa direcionada à composição das questões decorrentes da prática dos crimes.

Atenta às demandas relacionadas à proteção da vítima e à criação de mecanismos para efetivação de seus direitos, a "Declaração dos Princípios Fundamentais de Justiça Relativos às Vítimas de Crime e de Abuso de Poder”, adotada pela Resolução 40/34 da Assembleia Geral da ONU de 1985, enfatizou a necessidade de adoção, a nível nacional e internacional, de medidas que visem a garantia e o reconhecimento universal e eficaz dos direitos das vítimas. Segundo tal declaração, as vítimas são pessoas que

individual ou coletivamente, tenham sofrido um prejuízo, nomeadamente um atentado à sua integridade física ou mental, um sofrimento de ordem moral, uma perda material, ou um grave atentado aos seus direitos fundamentais, como consequência de atos ou de omissões violadores das leis penais em vigor num Estado membro, incluindo as que proíbem o abuso de poder (ONU, 1985).

É importante lembrar que a referida declaração ampliou o conceito de vítima para incluir "também os familiares próximos ou dependentes da vítima direta e as pessoas que tenham sofrido danos ao intervir para prestar assistência a vítimas em perigo ou para impedir a vitimação" (ONU, 1985).

Percebe-se até aqui que o fenômeno que retoma a importância do papel da vítima na resolução dos conflitos é relativamente recente e parece ter ligação com o movimento de internacionalização dos Direitos Humanos, que impulsionado pela vitimologia destaca a necessidade de atender aos interesses do ofendido, possibilitando sua efetiva participação dentro do processo de construção de uma solução ao litígio e protegendo sua dignidade através dos mais variados mecanismos de proteção, inclusive no plano internacional.

Nesse contexto, o processo de internacionalização dos Direitos Humanos parece ter exercido um papel fundamental no incentivo de práticas restaurativas que reclamam a participação do ofendido no plano de construção de soluções adequadas às questões penais mais complexas.

\section{A INTERNACIONALIZAÇÃO DOS DIREITOS HUMANOS E A RETOMADA DA IMPORTÂNCIA DO PAPEL DA VÍTIMA DENTRO DO PROCESSO PENAL}

O desenvolvimento do Direito Penal e a consequente substituição da vingança privada 


\section{A INTERNACIONALIZAÇÃO DOS DIREITOS HUMANOS E A RETOMADA DAS PRÁTICAS RESTAURATIVAS NO PROCESSO PENAL}

por sanções previamente estabelecidas em lei fez com que a vítima deixasse de exercer o protagonismo na solução das questões criminais.

Conforme ensina Câmara (2008, p. 46), "ao excluir a vítima da relação jurídico-penal o Estado, ainda que penetrado da correta intenção de promover a pacificação social, terminou por inviabilizar uma solução real dos conflitos - despersonalizando-os".

Ocorre que, após a $2^{\text {a }}$ Guerra Mundial e o martírio sofrido por judeus nos campos de concentração, a comunidade internacional voltou seus olhos novamente às questões envolvendo os interesses das vítimas, sendo que a relação havida entre o ofendido e o ofensor passou a ser analisada de um ponto de vista mais abrangente, o que reclamou uma normatização internacional acerca da temática.

Sem embargo, um dos principais motivos pelos quais os direitos das vítimas passaram a ser normatizados em larga escala no cenário mundial foi o surgimento da Organização das Nações Unidas em outubro de 1945.

A ONU, como é popularmente conhecida, trata-se de uma organização internacional cujos ideais estão expressos no preâmbulo de seu próprio documento de fundação - a Carta das Nações Unidas, onde se lê:

NÓS, OS POVOS DAS NAÇÕES UNIDAS, RESOLVIDOS a preservar as gerações vindouras do flagelo da guerra, que por duas vezes, no espaço da nossa vida, trouxe sofrimentos indizíveis à humanidade, e a reafirmar a fé nos direitos fundamentais do homem, na dignidade e no valor do ser humano, na igualdade de direito dos homens e das mulheres, assim como das nações grandes e pequenas, e a estabelecer condições sob as quais a justiça e o respeito às obrigações decorrentes de tratados e de outras fontes do direito internacional possam ser mantidos, ea promover o progresso social e melhores condições de vida dentro de uma liberdade ampla. E para tais fins praticar a tolerância e viver em paz, uns com os outros, como bons vizinhos, reunir as nossas forças para manter a paz e a segurança internacionais, e a garantir, pela aceitação de princípios e a instituição dos métodos, que a força armada não será usada a não ser no interesse comum,a empregar um mecanismo internacional para promover o progresso econômico e social de todos os povos.Resolvemos conjugar nossos esforços para a consecução desses objetivos.Em vista disso, nossos respectivos Governos, por intermédio de representantes reunidos na cidade de São Francisco, depois de exibirem seus plenos poderes, que foram achados em boa e devida forma, concordaram com a presente Carta das Nações Unidas e estabelecem, por meio dela, uma organização internacional que será conhecida pelo nome de Nações Unidas (ONU, 1945).

O surgimento da Organização das Nações Unidas em 1945 e a elaboração da Declaração Universal dos Direitos Humanos - DUDH em 1948 deu início a um processo de expansão das normas de caráter humanitário ao redor do planeta. Com a elaboração de diversos 
tratados internacionais voltados à proteção da pessoa humana e a constante preocupação dos Estados em evitar que minorias viessem a ser novamente martirizadas, iniciou-se uma expansão e internacionalização dos direitos humanos sem precedentes históricos.

A internacionalização dos direitos humanos constitui, assim, um movimento extremamente recente na história, que surgiu a partir do pós-guerra, como resposta às atrocidades $\mathrm{e}$ aos horrores cometidos durante o nazismo. Apresentando o Estado como o grande violador de direitos humanos, a Era Hitler foi marcada pela lógica da destruição e da descartabilidade da pessoa humana, o que resultou no extermínio de onze milhões de pessoas (PIOVESAN, 2016, p. 202).

Merece destaque o fato de que as normas internacionais de proteção da pessoa humana passaram a exigir uma posição ativa dos Estados no sentido de se promover a defesa dos grupos minoritários e das vítimas dos mais variados tipos de opressão. Por essa razão, o movimento de internacionalização dos direitos humanos afigurou-se como sendo de extrema relevância no processo de retomada da importância do papel da vítima dentro da resolução de conflitos.

Além de impulsionar uma ação global mais eficaz para proteção dos direitos, foi o movimento de internacionalização dos Direitos Humanos que, inclusive, tornou possível a responsabilização dos Estados quando as instituições nacionais se tornassem falhas ou omissas em seu dever de proteção.

[...] o conceito de responsabilidade no contexto internacional é muito mais coletivo que individual. Quando um agente ou funcionário do Estado erra e comete violação de direito de outrem, ou quando um tribunal interno deixa de aplicar um tratado vigente, negando eventual direito a um estrangeiro protegido por esse tratado, é o Estado para o qual o agente trabalha que, em princípio, responde pelo dano na órbita internacional (ainda que os indivíduos que o compõem nada tenham a ver com o ilícito cometido). [...]

A finalidade do instituto - também considerado por outros juristas como um princípio geral de Direito Internacional - é, em última análise, reparar e satisfazer, respectivamente, os danos materiais e éticos sofridos por um Estado em decorrência de atos praticados por outro (MAZZUOLI, 2016, p. 613).

Ainda no que diz respeito às normas internacionais de proteção às vítimas, vale mencionar a existência, no âmbito das Nações Unidas, de um sistema global de proteção aos Direitos Humanos cujos principais instrumentos normativos são a Declaração Universal dos Direitos Humanos (1948), o Pacto Internacional dos Direitos Civis e Políticos (1966) e o Pacto Internacional dos Direitos Econômicos, Sociais e Culturais (1966).

Juntos os instrumentos acima mencionados compõem a chamada "Carta Internacional dos Direitos Humanos" e possuem o objetivo primordial de fixar novos alicerces ideológicos para a comunidade internacional, promovendo a paz e o fortalecimento dos Direitos Humanos 


\section{A INTERNACIONALIZAÇÃO DOS DIREITOS HUMANOS E A RETOMADA DAS PRÁTICAS RESTAURATIVAS NO PROCESSO PENAL}

em todo o planeta. Esse sistema de proteção, por óbvio, se estende às vítimas, em seus mais variados aspectos.

Nesse mesmo contexto, ainda merecem destaque diversas normatizações internacionais elaborados com o apoio da ONU, as quais abordam a problemática acerca dos direitos humanos (incluindo as vítimas) em diferentes categorias. Tais normas buscam a conscientização e a responsabilização dos Estados em caso de violação dos direitos humanos.

Dentre estes instrumentos vale mencionar a Convenção Internacional sobre a Eliminação de todas as formas de Discriminação Racial (1965), a Convenção sobre a Eliminação de todas as formas de Discriminação contra a Mulher (1979), a Convenção contra a Tortura e outros Tratamentos ou Penas Crueis, Desumanos e Degradantes (1984), a Convenção sobre os Direitos da Criança (1990), a Convenção Internacional sobre a Proteção dos Direitos de todos os Trabalhadores Migrantes e dos Membros de suas Famílias (1990), a Convenção sobre os Direitos das Pessoas com Deficiência (2006) e a Declaração das Nações Unidas sobre os Direitos dos Povos Indígenas (2007),

Especificamente no que diz respeito à temática envolvendo as vítimas e a efetivação de um modelo inclusivo de procedimento penal, a Assembleia Geral da ONU editou a Resolução 40/34, de 29 de novembro de 1985, por meio da qual adotou a "Declaração dos Princípios Básicos de Justiça para as Vítimas de Delitos e Abuso de Poder", que prevê que o tratamento às vítimas seja feito com compaixão e respeito pela sua dignidade.

No início de seu texto a Resolução n 40/34 da Assembleia Geral da ONU “Afirma a necessidade de adoção, a nível nacional e internacional, de medidas que visem garantir o reconhecimento universal e eficaz dos direitos das vítimas da criminalidade e de abuso de poder", sublinhando, ainda, "a necessidade de encorajar todos os Estados a desenvolverem os esforços feitos com esse objetivo, sem prejuízo dos direitos dos suspeitos ou dos delinquentes" (ONU, 1985).

A Resolução 40/34 da Assembleia Geral da ONU reconhece a necessidade de adoção de medidas, tanto a nível nacional como internacional, para garantir o reconhecimento dos direitos das vítimas da criminalidade e de abuso de poder, sem que disto decorra prejuízo aos direitos dos suspeitos ou dos delinquentes. Seu texto revela ainda que a Declaração objetiva auxiliar os Estados e organismos envolvidos na busca pela justiça para as vítimas, elencando uma série de ações a serem adotadas pelos Estados-membros, entre as quais destacam-se as seguintes:

Adoção de medidas nas áreas da assistência social, saúde, educação, economia e prevenção da criminalidade, além de ajuda para vítimas carentes;

Incentivo dos esforços coletivos e de participação dos cidadãos na prevenção do crime; 
Mudanças na legislação e nas práticas existentes visando proibir atos contrários às normas internacionalmente reconhecidas no âmbito dos direitos do homem e de outros atos de abuso de poder;

Estabelecimento e reforço dos meios necessários à investigação, à prossecução e à condenação dos culpados da prática de crimes;

Colaboração internacional nos campos judiciário e administrativo, em domínios como o da investigação e o da prossecução penal dos delinquentes, da sua extradição e da penhora dos seus bens para os fins de indenização às vítimas (FRADE, 2011, p. 29-30).

Posteriormente, a resolução adotou a Declaração dos Princípios Básicos de Justiça Relativos às Vítimas da Criminalidade e de Abuso de Poder, que "visa ajudar os Governos e a comunidade internacional nos esforços desenvolvidos, no sentido de fazer justiça às vítimas da criminalidade e de abuso de poder e no sentido de lhes proporcionar a necessária assistência". (ONU, 1985) Além do mais, a referida declaração amplia o conceito de vítima e conclama os Estados a efetivarem medidas que garantam aos ofendidos os direitos de respeito à sua dignidade, à proteção integral, restituição, ressarcimento e à reparação dos danos porventura . Além disso, busca garantir o amplo acesso à informação, e o direito à indenização, inclusive por parte do Estado quando não for possível obtê-la do delinquente.

Como se vê, a maior parte das disposições constantes da Declaração dos Princípios Básicos de Justiça para as Vítimas de Delitos e Abuso de Poder tem por finalidade combater ou, quando menos, suavizar os efeitos das vitimizações secundária e terciária. (OLIVEIRA, 1999, p. 116)

Verifica-se, até aqui, um empenho da comunidade internacional no sentido de garantir a proteção às vítimas, incentivando a criação de modelos que possam atender às expectativas e necessidades dos ofendidos que, anteriormente, eram deixados à margem das questões envolvendo conflitos criminais.

Jesus (2006) ensina que diante da prática de uma infração penal, a Justiça Restaurativa pretende reunir o ofendido, seus familiares, o ofensor e os representantes da sociedade com a intenção de debaterem e encontrarem uma forma de solucionar determinado conflito, de modo a satisfazer a vítima. Nesse sentido, algumas alternativas penais, tais como o acordo civil, a transação penal, a mediação e outras opções modernas podem integrar, como instrumentos eficazes, esse meio de evitar os percalços de um processo criminal e a eventual aplicação da prisão como clássica resposta penal.

É importante lembrar que a Justiça Restaurativa "Não se trata de uma alternativa à Justiça Criminal, pois não pretende substituí-la. Cuida-se de um sistema auxiliar do Poder 
Judiciário, um meio de prevenção da criminalidade, apto a contribuir para a diminuição do número de infratores encarcerados" (JESUS, 2006).

Com vistas à criação de um locus capaz de possibilitar a interlocução das partes objetivando a construção de uma solução consensual para o litígio, a comunidade internacional passou a incentivar a implementação da chamada Justiça Restaurativa.

Nesse contexto, a Resolução n ${ }^{\circ}$ 12/2002 do Conselho Econômico e Social das Nações Unidas (ECOSOC), conceituou e definiu os programas de justiça restaurativa como sendo aqueles que lançam mão de procedimentos por meio dos quais o ofensor e qualquer dos afetados pelo crime participem, de maneira ativa e efetiva, da resolução do conflito, geralmente com o auxílio de um facilitador.

No referido instrumento, há um claro incentivo à adoção de programas de Justiça Restaurativa por parte dos países membros da ONU, fixando princípios básicos para sua implementação.

\section{$[\ldots]$}

6. Os programas de justiça restaurativa podem ser usados em qualquer estágio do sistema de justiça criminal, de acordo com a legislação nacional.

7. Processos restaurativos devem ser utilizados somente quando houver prova suficiente de autoria para denunciar o ofensor e com o consentimento livre e voluntário da vítima e do ofensor. A vítima e o ofensor devem poder revogar esse consentimento a qualquer momento, durante o processo. Os acordos só poderão ser pactuados voluntariamente e devem conter somente obrigações razoáveis e proporcionais.

8. A vítima e o ofensor devem normalmente concordar sobre os fatos essenciais do caso sendo isso um dos fundamentos do processo restaurativo. A participação do ofensor não deverá ser usada como prova de admissão de culpa em processo judicial ulterior.

9. As disparidades que impliquem em desequilíbrios, assim como as diferenças culturais entre as partes, devem ser levadas em consideração ao se derivar e conduzir um caso no processo restaurativo.

10. A segurança das partes deverá ser considerada ao se derivar qualquer caso ao processo restaurativo e durante sua condução.

11. Quando não for indicado ou possível o processo restaurativo, o caso deve ser encaminhado às autoridades do sistema de justiça criminal para a prestação jurisdicional sem delonga. Em tais casos, deverão ainda assim as autoridades estimular o ofensor a responsabilizar-se frente à vítima e à comunidade e apoiar a reintegração da vítima e do ofensor à comunidade (ONU, 2002).

Neste diapasão, entende-se que a Justiça Restaurativa criaria uma possibilidade para que haja uma verdadeira reformulação da sistemática processual, a qual poderia viabilizar o fortalecimento dos direitos da vítima, aqui compreendidos como uma questão de Direitos Humanos, incentivando a obtenção de soluções a partir de um consenso que também atenda aos interesses do ofendido. 
Nesse contexto, Baratta citado por Mazzutti (2012, p. 123-122) preleciona que

substituir parcialmente o direito punitivo pelo direito de reparação, outorgar à vítima e, geralmente, a ambas as partes dos conflitos entre particulares, maiores prerrogativas, de maneira que possam estar em condições de restabelecer o contato perturbado pelo crime, assegurar em maior medida os direitos de indenização das vítimas, são algumas das mais importantes diretrizes para a realização de um direito penal de intervenção mínima e para conseguir diminuir os custos sociais da pena..

É nesse sentido que o diálogo entre a vítima e o autor, pautado na consensualidade, voluntariedade, flexibilidade, arrependimento e reparação, rompe com o paradigma punitivo e marca a inclusão desses sujeitos na justiça penal a partir de uma resolução de conflitos pautada no coletivismo, respeitando e garantindo os direitos humanos e as liberdades individuais inerentes ao ser humano.

Nota-se que a comunidade internacional vem buscando implementar medidas para proteção das vítimas que, inclusive, tornaram possível a responsabilização dos Estados quando as instituições nacionais forem omissas ou não se mostrarem eficazes. Percebe-se, nesse contexto, um claro incentivo para que os governos adotem medidas efetivas de promoção aos direitos das vítimas.

\section{CONCLUSÃO}

A Justiça restaurativa se apresenta como um novo modelo que pode ser aplicado ao processo penal na busca de auxiliar as partes envolvidas na criação de uma solução adequada aos conflitos ocasionados pelo crime. Seu principal objetivo é restaurar as relações eventualmente abaladas a partir do evento criminoso possibilitando a criação de um locus democrático e facilitador do consenso entre vítima e ofensor.

Conforme verificado ao longo do trabalho, houve um período que se findou após o término da $2^{\text {a }}$ Guerra Mundial onde as vítimas foram alijadas do processo de construção de soluções para as ofensas por elas sofridas, eis que a prática de qualquer ato criminoso era vista como um atentado ao poder do próprio Estado.

Por outro lado, após o holocausto e o consequente início do movimento de internacionalização dos direitos humanos, passou a existir uma série de tratados internacionais que tutelam os interesses dos ofendidos no âmbito do processo criminal, os quais incentivam a participação das vítimas na construção de decisões que também atendam a suas conveniências, 
demandas e interesses.

O movimento de internacionalização dos direitos humanos tem exercido um papel de extrema importância no incentivo ao respeito à vontade daquele que sofreu uma ofensa apta a dar supedâneo à instauração de um processo criminal, isto é, a vítima. Nesse contexto, verificase que a ampliação das normas de caráter humanitário deram ensejo a uma verdadeira exortação à implementação de práticas restaurativas que atendam às conveniências e aos interesses das vítimas.

Ao submeter-se aos tratados internacionais e demais instrumentos normativos que tutelam o direito da vítima, o Estado incorpora normas desta natureza e acaba por colocá-las no núcleo de validade de sua própria ordem jurídica, o que serve de incentivo para o surgimento de novas formas de solucionar conflitos que sejam capazes de atender também aos anseios da vítima.

A implementação de práticas restaurativas a partir do incentivo fornecido pelos tratados internacionais afigura-se como sendo uma possibilidade para a criação de espaços normativos dentro da sistemática processual penal (ou até para além dela) numa tentativa de subversão da ordem vigente de maneira a ampliar e proteger os interesses fundamentais inerentes às partes que figuram como vítimas de um fato criminoso.

O respeito ao interesse da vítima na busca por uma solução adequada às questões impostas pela prática de um delito não implica em deixar de lado os direitos e garantias que necessariamente devem ser assegurados ao ofensor. Pelo contrário, o que se espera da prática restaurativa é que todos os envolvidos com o caso possam compartilhar entendimentos, perspectivas e motivações, buscando um consenso restaurador, capaz de satisfazer a todos de uma maneira mais plena e eficaz.

É importante destacar que o incentivo às práticas restaurativas no cenário internacional ainda se trata de fenômeno relativamente recente e encontra óbice na dificuldade de resolver problemas de cunho operacional. Por essa razão, há necessidade de se preparar e capacitar os agentes técnicos envolvidos na concretude da Justiça Restaurativa, sobretudo a fim de possibilitar a execução efetiva das medidas eventualmente acordadas pelas partes.

Embora ainda sejam pioneiras, as iniciativas que atualmente se desenham para a aplicação das medidas restaurativas levam consigo a responsabilidade de superar as dificuldades que inicialmente se apresentam e impulsionar a efetivação da Justiça Restaurativa como instrumento para efetivação de Direitos Humanos. 


\section{REFERÊNCIAS}

BRASIL, Deilton Ribeiro. A justiça restaurativa como estratégia de tratamento de conflitos. In: Athenas, Revista de Direito Política e Filosofia. Disponível em: $<$ http://www.fdcl.com.br/revista/site/download/fdcl_athenas_ano3_vol2_2014_artigo11.p df $>$ Acesso em 24 de nov. 2016

BRASIL, Decreto $n^{\circ} 19.841$ de 22 de outubro de 1945. Carta das Nações Unidas. Disponível em: $<$ http://www.planalto.gov.br/ccivil 03/decreto/1930-1949/d19841.htm $>$. Acesso em 21 abr. 2017

CÂMARA, Guilherme Costa. Programa de Política Criminal: Orientado para a Vítima de Crime. São Paulo: Revista dos Tribunais, 2008.

FRADE, Edilson Vlademir de Almeida. Direitos da vítima na criminalidade. Dissertação (Mestrado) apresentada ao Curso de Pós-Graduação em Direito da Faculdade de Direito da Universidade do Rio Grande do Sul. Porto Alegre, 2011.

JESUS, Damásio de. Organização das Nações Unidas (ONU) recomenda a adoção da Justiça Restaurativa. São Paulo: Complexo Jurídico Damásio de Jesus, maio 2006. Disponível em: <www.damasio.com.br $>$. Acesso em 21 abr. 2017.

LLEWELLYN, Jennifer J. e HOWSE, Robert. Restorative Justice: a conceptual framework. Disponível em: $<$ https://dalspace.library.dal.ca/>. Acesso em 16 abr. 2017.

LOPES JR, Aury. Direito Processual Penal. São Paulo: Saraiva, 2014.

MAZZUTTI, Vanessa de Biassio. Processo penal sob a perspectiva da vítima: uma leitura constitucional a partir dos direitos humanos. Curitiba: Juruá Editora, 2012.

OLIVEIRA, Ana Sofia Schmidt de. A Vítima e o Direito Penal. São Paulo: Revista dos Tribunais, 1999.

ORGANIZAÇÃO DAS NAÇÕES UNIDAS. Declaração dos Princípios Básicos de Justiça Relativos às Vítimas da Criminalidade e de Abuso de Poder - 1985. Disponível em:

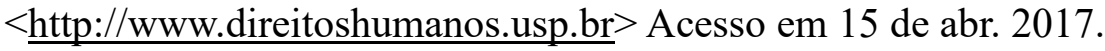

ORGANIZAÇÃO DAS NAÇÕES UNIDAS. ECOSOC Resolution 2002/12. Disponível em:

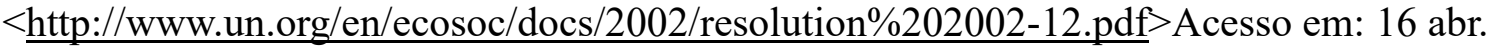
2017.

ORGANIZAÇÃO DAS NAÇÕES UNIDAS. Resolução 40/34 da Assembleia Geral da ONU. Disponivel em: $<$ http://www.dhnet.org.br/direitos/sip/onu/ajus/prev29.htm $>$ Acesso em: 16 abr. 2017.

ORTEGAL, Leonardo. Justiça Restaurativa: um caminho alternativo para a resolução de conflitos. In. Revista do Conselho Nacional de Política Criminal e Penitenciária. V.1, n.21, 2008, p.121-132. 
PEDROSO, João; TRINCÃO, Catarina; DIAS, João Paulo. Por caminhos da(s) reforma(s) da Justiça. Coimbra: Coimbra Editora, 2003.

PIOVESAN, Flávia. Direitos humanos e o direito constitucional internacional. São Paulo: Saraiva, 2016.

PRANIS, Kay. Processos circulares. Trad. Tônia Van Acker. São Paulo: Palas Athena, 2010.

PRUDENTE, Neemias Moretti. Justiça restaurativa e experiências brasileiras. In:

SPENGLER, Fabiana Marion; LUCAS, Douglas Cesar (Org.). Justiça restaurativa e mediação: políticas públicas no tratamento dos conflitos sociais. Ijuí: Editora Ijuí, 2011.

ROBALO, Teresa Lancry de Gouveia de Albuquerque e Sousa. Justiça restaurativa: um caminho para a humanização do direito. Curitiba: Editora Juruá, 2012.

SICA, Leonardo. Justiça restaurativa e mediação penal: o novo modelo de justiça criminal e gestão do crime. Rio de Janeiro: Lumen Juris, 2007.

TELLO, Nancy F. A justiça restaurativa: um programa integral de atenção e prevenção do delito. In: Revista IOB de Direito Penal e Processual Penal, São Paulo, no 52, out./nov. 2008 .

UNICEF. Manual Sobre o Protocolo Facultativo Relativo à Venda de Crianças, Prostituição Infantil e Pornografia Infantil. Disponível em: $<\underline{\text { https: } / / \text { www.unicef- }}$ irc.org/publications/pdf/optional_protocol_por.pdf>. Acesso em 26 de nov. 2016.

ZAFFARONI, Eugenio Raúl; ALAGIA, Alejandro; SLOKAR, Alejandro. Derecho Penal, Parte General. 2. ed. Buenos Aires: Ediar, 2002.

ZEHR, Howard. Justiça restaurativa: teoria e prática. Tradução de Tônia Van Acker. São Paulo: Palas Athenas, 2012.

ZEHR, Howard. Trocando as lentes: um novo foco sobre o crime e a justiça. Tradução de Tônia Van Acker. São Paulo: Palas Athenas, 2008. 